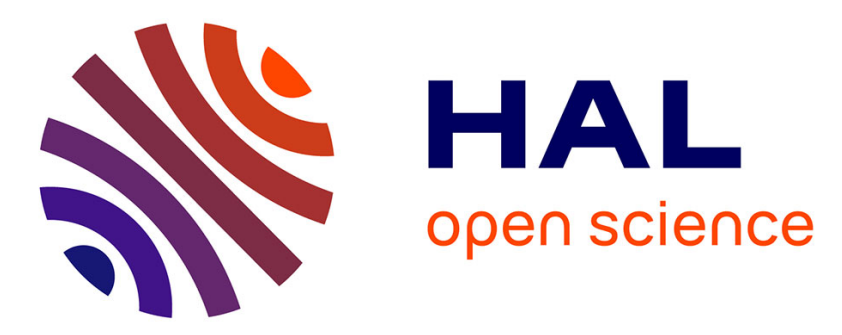

\title{
Dynamics of Socio-Economic Systems: Attractors, Rationality and Meaning
}

\author{
Andrzej Nowak, Jørgen Vitting Andersen, Wojciech Borkowski
}

\section{To cite this version:}

Andrzej Nowak, Jørgen Vitting Andersen, Wojciech Borkowski. Dynamics of Socio-Economic Systems: Attractors, Rationality and Meaning. Review of Behavioral Economics, 2015, 2 (1-2), pp.167-173. 10.1561/105.00000026 . hal-01215581

\section{HAL Id: hal-01215581 \\ https://hal.science/hal-01215581}

Submitted on 19 Oct 2015

HAL is a multi-disciplinary open access archive for the deposit and dissemination of scientific research documents, whether they are published or not. The documents may come from teaching and research institutions in France or abroad, or from public or private research centers.
L'archive ouverte pluridisciplinaire HAL, est destinée au dépôt et à la diffusion de documents scientifiques de niveau recherche, publiés ou non, émanant des établissements d'enseignement et de recherche français ou étrangers, des laboratoires publics ou privés. 


\title{
Dynamics of Socio-Economic systems: attractors, rationality and meaning ${ }^{1}$
}

\author{
Andrzej Nowak ${ }^{2,3}$ \\ Jorgen Andersen 4 \\ Wojciech Borkowski ${ }^{5}$ \\ nowak@fau.edu
}

Social sciences are undergoing rapid change. Due to rapid developments of computer simulations of social processes and availability of big data social sciences are becoming increasingly precise and integrated. Finally the formal tools that can capture complex human and social dynamics have been developed and data for verification of quantitative models of social processes are becoming available. The time is becoming ripe for the social sciences to undergo radical transformation, integrate fragmented theories and formulate quantitative models.

The paper by Gintis and Helbing is an attempt to propose a theoretical framework for the development of an integrated theory of human social dynamics. Gintis and Helbing go beyond traditional boundaries of scientific disciplines and propose integration of major theories from economy, sociology, anthropology, social psychology, biology, using formalisms of economy, physics, mathematical game theory, computer simulations and dynamical systems approach. They aim to integrate into a single theoretical framework: rational decisions, non-monetary motivations, social norms, evolutionary

\footnotetext{
${ }^{1}$ This work was supported by funds from Polish National Science Centre (project no. DEC- 2011/02/A/HS6/00231).

${ }^{2}$ Institute for Social Studies, University of Warsaw

3 Florida Atlantic Univresity

${ }^{4}$ CNRS, Centre d'Economie de la Sorbonne, University of Paris 1

${ }^{5}$ University of Social Sciences and Humanities
} 
dynamics and the role of institutions. The scope of proposed integration is breathtaking. The proposed generalizations to Walrasian general equilibrium model (Arrow and Debreu 1954) e.g., the assumption that human are motivated by many types of rewards, not only monetary gains, agrees well what is known in psychology. Very interesting is the notion of correlated equilibrium. Many of the specific comments are insightful. Several of the assumptions, however, may be challenged. In sum the theory is a good introduction to the discussion of what should be the general assumptions of a general theory of social processes.

\section{Equlibrium}

Gintis and Helbing adopt the assumption of Walrasian models of economy concerning the existence of equilibrium in social systems. This assumption is fundamental for standard economic theory. In the language of dynamical systems approach the notion of equilibrium corresponds to fixed-point attractor. The notion of equilibrium has a long history in the social sciences. Both in biology (Cannon 1029) and psychology the notion of homeostatic and later multi-static self-regulation was based on the notion that systems dynamics is aimed at maintaining and restoring equilibrium. In psychology, for example, the homeostatic mechanism of optimal level of stimulation, where overstimulation resulted in exhaustion and under stimulation in boredom (Berlyne 1960) replaced the earlier one directional notion of reduction of unpleasant states such as anxiety or dissonance. It was also proposed that stable states represent various personal and social standards (Carver and Scheier 1999)

The notion of attractor is one of the most useful dynamical systems concepts for describing social dynamics. The concept of attractor allows one to combine the notion of constant change, ever-present in social and metal systems with the notion of stability. Dynamics processes evolve around their attractors, which are relatively stable. Thoughts and feelings of individuals change all the time, but they tend to converge on attitudes that function as attractors and change on a slower time scale. Self-relevant thoughts vary in time but their evaluative tone tends to converge on self-esteem, which functions as an attractor for self-relevant thoughts. If self-view is perturbed by new information or external influence; self-esteem maintenance mechanisms tend to reinstate self-esteem. 
Not all the social and psychological processes, however, are characterized by attractor dynamics. Even the same process, depending on control parameters, may have attractors or not. With respect to regulation of mood, for example, the research on individuals with diagnosed depression, for example, has shown (Johnson \& Nowak 2002) that for some depressed individuals depressed mood state functions as attractor, for some others no attractor for mood exists. Correlations with clinical data have shown that the lack of attractor is strongly associated with multiple hospitalizations and suicidal tendencies.

With respect to intractable conflict, the state of negative relations between the parties functions as an attractor. Lack of the negative relations attractor indicates a healthy relationship. With respect to many social processes whether they have the attractor is important information about the system, rather than a universal feature of their dynamics.

Since psychological and social systems constantly evolve and change on various time-scales the appearance of an attractor in their dynamics and the characteristic of this attractor is likely to be a temporary phenomena. Attractors also evolve but on a slower time scales. The relation between different time scales is well described by synergetics (Haken 1980), where at fast time scales dynamics variables evolve around what looks like stable attractors. On longer time scales the momentary states of the dynamic variables are practically invisible, so they are observed at values of their attractors, and what is visible is the dynamics of the attractors.

In sum, social systems are practically always in flux, although in different time scales. Specific processes, for some time, and in some conditions may have attractors. It is important information if they do. Real social systems are composed of multiple interconnected processes occurring in different time scales. It is unlikely that all the processes tend toward equilibrium. Even, if it sometimes is the case, it should be a result of analysis of empirical data, rather than a priori assumption. The dynamics of simplified mathematical or computer simulation models are, however, likely to converge on attractors i.e. be characterized by equilibrium tendencies. It is similar to the Hardy - Weinberg law/principle in biology which states that "allelic and genotypic frequencies remain constant absent evolutionary influences. These 
influences include non-random mating, mutation, selection, genetic drift, gene flow and meiotic drive." (c.f. Goo, S,W., \& Thompson 1992). The assumptions under which the equilibrium exists almost never are satisfied in longer time spans. In shorter timescales, in ecosystems, also oscillations, like in the Lotka-Volterra model, may describe typical dynamics, rather than static equilibrium. Because of external disturbances, even these stable oscillatory patterns almost never remain for a long time.

\section{Rationality}

One of the most interesting features of Gintis and Helbing theoretical framework is that they go beyond traditional economic theory assuming that humans decisions are driven by all kinds of motives, including purely altruistic motives as well as probabilistic outcomes. Norms also can be couched in terms of utility of outcomes, mostly as factors that modify the utility functions of decision makers. Gintis and Helbing assume that individuals combine all the utilities factoring the probabilities of outcomes and make the decision that maximizes subjective expected utility. They assume that the preferences are transitive, and that assessment of outcomes does not influence subjective probabilities.

Current research in psychology and marketing casts doubts on the views of humans as rational decision makers, even when the meaning of rationality is relaxed, like in $\mathrm{GH}$ framework. GH propose how to improve the traditional models of decision making, but arguably we need a new model, based on different principles. Human choices are often driven by emotions rather than cognitive processes, are strongly influenced by unconscious processes rather than considerations of options and calculation of probabilities, often are unconscious, and frequently their outcomes depend on social, rather then individual processes.

As Ormerod (1995) points out, in today's world there are so many products that comparing them all is impossible, many of the products are so technically sophisticated and complex, that buyers are not competent to understand their features. Situations when a decision maker can list all the decision options, assess utilities and probabilities of the outcomes, consider various own motives and make decision on the full comparison of all the products is extremely rare. One of us (AN) witnessed just once a person following this model in consumer decision. The choice of electronic camera, took two weeks, 
several hours a day of research and comparing the products. It resulted in the choice of really a very good product. Rarely individuals have enough time, skills and motivation to invest so much in a decision. Just as an example AN just followed this choice in his own purchase and then recommended this product to others, who also bought the product.

Consumers, when comparing products, usually concentrate only on very few aspects of the product, not necessarily the one that are most relevant. Since they are likely to consider different aspects of the item when comparing it with different items, the choices are likely to be non-transitive. For example computer A is better than B because it is faster and has better screen, computer $\mathrm{B}$ is better than $\mathrm{C}$ because its battery lasts longer. Computer $\mathrm{C}$ is better than $\mathrm{A}$, because it is lighter and looks better. The features on which an item is evaluated depend on the item it is compared with, situational context, but also on other individuals with whom the individual compares the product.

In many cases individuals do not evaluate the product, but rather they adopt the evaluation of others either in direct interaction, or from product rating by expert reviews or Internet evaluations by other users. In such cases the structure of contacts in social networks, and product adoption by linked others has more impact on products adoption than the features of the product.

One of the core elements of the approach proposed by Gintis and Helbing is that different types of outcomes are combined in function, that adds up utility coming from different sources, of each decision option, for example, financial outcomes, satisfying norms, altruistic etc.

Constructing a general function of satisfaction that combines different types of outcome (e.g. financial consequences and personal values) may be difficult and such a function cannot simply add the satisfaction with different outcomes, because different types of motivation are not independent; external motivation tends to replace any internal one - moral or normative - that might have formed (Deci, Koestner \& Ryan, 1999; Frey \& Jegen, 2001).

The model assumes that individuals can assess probability of various outcomes. Individuals often relay on narratives in forming the expectation of the likely course of action, rather than consider all the possible outcomes assigning probabilities to each of them. The expected probability can thus change with the change of the narrative. 
Probability thus may be the result of social construction rather than individually assessed likelihood.

\section{Direct and indirect interactions}

Gintis and Helbing go beyond standard economic models in assuming the importance of patterns of interaction between individuals, described as social networks. They also assume that individuals influence each other through artifacts, for example artifacts of culture. In economy, another distinction is also important when considering social dynamics. Economic phenomena depend both on direct and indirect interactions between individuals (Andersen \& Nowak 2013). In direct interactions individuals transmit information or exert influence on each other (Nowak, Vallacher \& Miller 2003). The structure of such interactions is well described by social networks linking individuals. However individuals also interact in indirect ways, through mechanisms of the market and financial institutions. Decisions to buy or sell have consequences for other individuals. These consequences, for example, are experienced as changing prices.

\section{Meaning}

Social systems are different from physical and biological systems because their dynamics are based on meaning. Social reality is constructed in interactions between individuals, social interactions are necessary to sustain it. (Vygotsky 1978, Berger \& Luckmann 1991). In contrast to physical phenomena, properties of social reality depend more on the social process than on their objective properties, social reality is being constructed and maintained in social interactions. Social constructs are the results of human decisions rather than objective reality. People constantly search for the meaning of the situation they are in, what the others are doing and their own actions. Decisions and actions of individuals depend on their understanding of the situation rather then their objective properties. The meaning created in social interactions has causal effect; it decides about the shape of social processes and their course. From this perspective the social and economic processes, in fact are socially constructed. It is thus difficult to analyze social 
and economic processes as if they existed, like physical processes in objective form. The capacity to include socially created meaning may be an important feature of a general theory of social processes.

\section{References}

Anderson, Jorgen and Andrzej, Nowak. 2013. Introduction to Socio-Finance. Heidelberg: Springer.

Arrow, Kenneth J., and Gerard Debreu. 1954: "Existence of an equilibrium for a competitive economy." Econometrica: Journal of the Econometric Society 265-290.

Berger, Peter L. and Thomas Luckmann. The Social Construction of Reality: A Treatise its the Sociology of Knowledge . New York: Garden City: Anchor Books, 1966) Berlyne, Daniel E. "Conflict, arousal, and curiosity." New York: McGraw-Hill (1960). Cannon, Walter, B. 1929_. “Organization For Physiological Homeostasis”. Physiological Reviews; 9 No. 3: 399-431.

Carver, Charles. S., \& Michel, F., Scheier. 1999. "Themes and issues in the selfregulation of behavior". Advances in social cognition, 12, 1-105.

Deci, Edward., L.,Richard Koestner, and Richard, M., Ryan. 1999. “A meta-analytic review of experiments examining the effects of extrinsic rewards on intrinsic motivation." Psychological Bulletin, 125(6), 627-668. doi: 10.1037/00332909.125.6.627

Frey, Bruno S., and Reto Jegen. 2001 "Motivation crowding theory." Journal of economic surveys 15 , no. $5: 589-611$.

Guo, Sun Wei, and Elizabeth A. Thompson. 1992. "Performing the exact test of Hardy-Weinberg proportion for multiple alleles." Biometrics: 361-372.

Haken, Hermann. 1980. "Synergetics-are cooperative phenomena governed by universal principles." Naturwissenschaften 67, no. 3: 121-128.

Johnson Sheri and Andrzej Nowak. 2002 Dynamical Patterns in bipolar depression Personality and Social Psychology Review 6, 370-379. 
Nowak, Andrzej., Robin R. Vallacher and Mandy. Miller, E. (2003)., ,Social influence and group dynamics"., Handbook of psychology: Vol. 5. Personality and social psychology edited by In I. Weiner (Series Ed.) \& T. Millon \& M. J. Lerner (Vol. Eds.) pp. 383-417. New York: Wiley.

Ormerod, Paul. The death of economics. New York: Wiley (1995).

Vygotsky, Lev, S. 1978. Mind and society: The development of higher mental processes. Cambridge, Massachusets: Harvard University Press 